OPEN ACCESS

Edited by:

Duarte Araújo,

University of Lisbon, Portugal

Reviewed by:

Ivan Cuk,

Singidunum University, Serbia

Pedro Teques,

Polytechnic Institute of Maia, Portugal

${ }^{*}$ Correspondence:

Dominika Wilczyńska

domiwilczynska@gmail.com

Specialty section:

This article was submitted to

Movement Science and Sport

Psychology,

a section of the journal

Frontiers in Psychology

Received: 11 September 2020 Accepted: 01 March 2021

Published: 24 March 2021

Citation:

Jaenes JC, Wilczyńska D, Alarcón D,

Peñaloza $R$, Casado $A$ and Trujillo $M$

(2021) The Effectiveness of the

Psychological Intervention in Amateur

Male Marathon Runners.

Front. Psychol. 12:605130.

doi: 10.3389/fpsyg.2021.605130

\section{The Effectiveness of the Psychological Intervention in Amateur Male Marathon Runners}

\author{
Jose C. Jaenes ${ }^{1}$, Dominika Wilczyńska ${ }^{2 *}$, David Alarcón ${ }^{1}$, Rafael Peñaloza ${ }^{3}$, \\ Arturo Casado ${ }^{4}$ and Manuel Trujillo ${ }^{5}$ \\ ${ }^{1}$ Department Social Anthropology, Basic Psychology and Public Health, University Pablo de Olavide, Seville, Spain, \\ ${ }^{2}$ Department of Social Science, Gdansk University of Physical Education and Sport, Gdańsk, Poland, ${ }^{3}$ Faculty of Higher \\ Studies Zaragoza, Psychology Career, National Autonomous University of Mexico, Mexico City, Mexico, ${ }^{4}$ Centre for Sport \\ Studies, Rey Juan Carlos University, Madrid, Spain, ${ }^{5}$ School of Medicine, New York University, New York City, NY, \\ United States
}

Background: The Marathon runners must have the proper technical preparation to reach excellence and to achieve adequate psychological preparation for the race. Against this background, the current study aims to describe the implementation results of a cognitive-behavioral intervention based on psychological skills training for marathon runners.

Methods: Fourteen amateur male marathoners with an average age of 30 ( $S D=5.75$ ) were trained with various emotional and cognitive control techniques to enhance their performance in competition. Various psychological variables, related to the subjects level of perceived stress, and to qualitative characteristics of their thoughts were measured before and after the target marathon race. Results were analyzed through non-parametric tests for two related samples. The Cohen's $d$ effect size for single-group pretest-posttest repeated measures were also performed.

Results: Statistical analysis reveals that, controlling for age and running experience, the intervention decreased significantly the level of perceived stress and the occurrence of negative thoughts before the race, during, and after the race.

Conclusion: Training in cognitive control and relaxation techniques, as part of the psychological skills training could determine the quality of performance of marathon runners.

Keywords: psychological preparation, track and field athletes, performance, negative thoughts, anxiety

\section{INTRODUCTION}

Running long distances, specifically a 42,195 -meters race, is a physically and psychologically demanding task. While elite runners can complete it in just over $2 \mathrm{~h}$, recreational runners rarely finish the race in under $3 \mathrm{~h}$, and many can take up to five or more hours. Sport psychology researchers became interested in this demanding distance sport in the 1970s and 80 s, investigating different aspects of the athletes involved, such as commitment (Carmack and Martens, 1979; Joseph and Robbins, 1981), runners psychosocial characteristics (Gontang et al., 1977; Freischlag, 1981; Summers et al., 1983), the presence of running addiction (Little, 1976; Sachs, 1982; Sacks, 1982; Glasser, 1985; Morgan et al., 1987; Jaenes, 1994; Szabo et al., 1997), or the use of a marathon race as an adjuvant in psychotherapy in order to 
attenuate the impact of selected psychiatric, psychosomatic, and somatic syndromes (Solomon and Bumpus, 1978).

Previous research focuses on marathoner's psychological characteristics such as their level of anxiety (Masters and Lambert, 1989), the possible relationship between cognitive and somatic anxiety with self-confidence (Jaenes, 1994; Jaenes and Caracuel, 2016), and the socio-demographic predictors of anxiety level among runners (Ruiz-Juan and Zarauz, 2014; Ruiz-Juan et al., 2016). Studies regarding cognitive and somatic anxiety, have reported that marathoners are, in many cases, individualists, and as such, they perform better when their level of cognitive anxiety is medium to high (Raglin and Hanin, 2000; Jaenes and Caracuel, 2016). Other authors observed that the most successful runners showed minimal rates of undesirable moods and some adverse emotional characteristics such as anger, fatigue, depression, and confusion, while reporting higher rates of "vigor" (Morgan and Pollock, 1977; Okwumabua et al., 1983; Morgan et al., 1987). Elite marathoners are also characterized by intrinsic motivation, and by a very high level of motivation to achieve goals (Morgan et al., 1987; Foster and Walker, 2005). Other authors have reported these athletes' high levels of hardiness (Jaenes et al., 2009), and the capacity to experience "flow state" while achieving their best results (Fernández Macías et al., 2015). Studies which compare long-distance runners of different performance levels show that higher performance level athletes are significantly more focused on their specific training activities and tended to have more fun performing these activities, than lower-level runners (Casado et al., 2014; Casado and Ruiz-Pérez, 2017).

Running addiction, and its predictors among long-distance runners, has also been investigated (Ruiz-Juan and Zarauz, 2012; Ruiz-Juan et al., 2019), together with running addiction consequences such as the presence of eating disorders (Yates, 1987, 1991; Hausenblas and Carron, 1999; Davis and Strachan, 2001; Yates et al., 2010). Some authors also tested the impact on runners of different intervention methods, such as the cognitive association-dissociation technique (Okwumabua et al., 1983; Schomer, 1986, 1987; Takai, 1996, 1998; Wulf, 2013; Brick et al., 2014).

Research results have consistently supported the idea that psychological skills training (PST) can increase an athletes' sport enjoyment and performance (Martin et al., 2012). The importance of PST in the development of athletic performance is widely recognized (Birrer and Morgan, 2010), even in long-distance runs (Thelwell and Greenlees, 2003). PST better demonstrates its efficacy when used in participants in highintensity sports, as it facilitates the interpretation of cognitive and somatic sensations, helps the athlete to manage pain, and to use associative attentional techniques (Birrer and Morgan, 2010). PST techniques also help in managing the intensity and directional dimensions of competitive anxiety when relaxation techniques are added (Wadey and Hanton, 2008). According to McCormick et al. (2015), in a systematic literature review, PST consistently improves endurance performance, and thus benefits endurance athletes. There are studies focused on the use of cognitive strategies (Schomer, 1986, 1987), to reduce anxiety and increase self-confidence (Jaenes and Caracuel, 2016), and on the utility of Riera's skill training (Riera, 2005, 2010). Based on the cumulative effect of this research on professional athletes, the current study investigates the impact of cognitive-behavioral intervention, based on psychological skills training (PST) on amateur athletes who practice marathons, a population far larger and less studied than that of elite runners.

The PST program appeared to foster relaxation, concentration, and refocusing skills in young gymnasts (Fournier et al., 2005). Vesković et al. (2019) studied the effects and effectiveness of a psychological skills training program on the optimization of anxiety and self-confidence in a group of karate athletes. Fletcher and Hanton (2001) demonstrated the efficacy of the PST program in swimmers using relaxation strategies to reduce and interpret their intensity levels. Similar results were found about the effect of two different psychological methods of skills training-self-talk and goal setting-on youth swimmers' swimming performance (Meggs and Chen, 2019). The 5-week psychological skills intervention program effectively improved youth swimming performance (Meggs and Chen, 2019). Schuler and Langens (2007) investigated the buffering effects of self-verbalization in a marathon race in two different studies, in the first study they found that a major psychological crisis occurs around kilometer 30, a crisis characterized by a strong urge to disengage from the goal and thoughts about benefits and costs, and that this crisis had negative effects on race performance. In a second study, the use of self-verbalizations was experimentally induced. The results confirmed the hypothesis that self-talk effectively buffer against the psychological crisis's adverse effects on race performance.

Despite the demonstrated effectiveness of PST interventions in the athletes' population, resistance to the use of PST has been reported often, and it can be related to the presence of barrier such as gender (Gnacinski et al., 2017). This study confirms that female athletes are more receptive and open to sport psychology consultation than male athletes. Female athletes are more willing to work with a sport psychologist, are less likely to stigmatize services, and have more trust in the usefulness of psychological skills training consultations than male athletes. Research on athletes' expectations has also found female athletes to be more committed (e.g., higher levels of self-responsibility, openness, and motivation) to the sport psychology consulting process than their males counterparts (Martin, 2005; Wrisberg et al., 2009; Martin et al., 2012). Therefore, this study will also assess the influence of a 7-week intervention, based on selected PST techniques, specifically on male recreational athletes. This PST intervention has been designed to help marathon runners to cope with the psychological demands of the race by providing them with skills and techniques to deal with their emotional challenges. We hypothesize that the PST intervention will decrease participants' experienced stress and negative thoughts about the race.

\section{METHODS}

\section{Participants}

Fourteen male amateur marathon runners with an average age of $30(S D=5.75)$ participated in the current study. All the participants were recruited at the Andalusian Center of Sport 
TABLE 1 | Athletes' mental state self-reported questionnaire.

1. Before the marathon, I am concerned about the race.

2. Before the marathon, I am concerned I may not do as well in this race as I could.

3. During the marathon, I am worried about reaching my goal.

4. During the marathon, I am concerned about shocking under pressure.

5. During the marathon, I am concerned I will not be able to concentrate.

6. During the marathon, I am concerned about performing poorly.

7. After the marathon, I am concerned about wasting more mental energy that was necessary.

8. After the marathon, I have self-doubts about that I had performed as I should.

Items were answered on a Likert scale ranging from 1 (totally disagree) to 5 (totally agree).

Medicine (CAMD) where they were participating voluntarily in psychological training with a sport psychologist. The majority of subjects had finished a minimum of three marathons, and an average of 16 years of experience $(S D=5.11)$. All the subjects were registered to participate in the 2017 Seville International Marathon held in Spain.

\section{Materials}

For the intervention, a recording with the Progressive Jacobson Relaxation Technique adapted to long-distance runners was used. This kind of technique is commonly practiced by athletes while participating in psychological training in the Psychology Services at Andalusian Center of Sport Medicine. The relaxation practice was recorded on a Redmi Note 6 Pro Telephone Terminal, during the group session (lasting $12 \mathrm{~min}$ and $16 \mathrm{~s}$ ), which was sent to the terminals of all participants. To assess the athletes' mental state, a self-report measure was created for purpose of the present study, most of the items were based on the validated Spanish version of the Competitive State Anxiety Inventory 2 (CSAI-2R) questionnaire (Fernández et al., 2007), and the others items were created for purpose of the present study, see Table 1 . The instrument consisted of 8 statements: two statements described probable negative thoughts before the race, the next four described possible negative thoughts during the race, and the last two statements characterized the self - doubts and mental load, the participants could experience after the race. All items were answered on a 5-point Likert scale ranging from 1 (totally disagree) to 5 (totally agree).

\section{Procedure}

Previous studies reported that the Psychological Skill Training (PST) technique was one of the most effective psychological interventions in sports (Neil et al., 2006; McCormick et al., 2015). The intervention program was based on the PST principles (Weinberg and Gould, 2014), and the sport classifications and interactions of Riera (2005, 2010). The cognitive-behavioral techniques employed in the PST program were selected according to the psychologists' experience training marathon runners, and by the recent literature about its efficacy. The following cognitive-behavioral techniques were employed in the PST program:
Cognitive Association technique: running focus on the pace, running pack, breathing, scanning muscular sensations, selftesting and monitory their body, making mind maps, underlying key words, self-positive messages, etc. For instance, when the attention was focused on the body, physical sensations, pain, the focus is internal.

Cognitive dissociation technique: when the attention was focused on anything than other and internal sensations, is dissociation (Master and Ogles, 1998). For instance, thinking on the family, and friends, other races, observing public attitudes during the race, etc. Rodríguez et al. (2017) has studied the influence of association and dissociation cognitive strategies on different physiological variables, in a group of experienced long distance runners in a controlled condition in laboratory, and how both strategies affect performance at different running pace.

Thought-stopping technique: is a cognitive technique involving mental or behavioral aspects (Zinsser et al., 2006). The aims are to disrupt negative thinking patterns, removing, replacing, and redirect problematic thoughts to something that helps relieve distress. Otherwise, focusing on the relevant stimulus while running and disrupt unwanted thoughts. It is an active process of suppressing self-doubts, negative ideas along 42 kilometers, through the personalized self-talk to enhanced performance (Magnusson and van Roon, 2013).

Jacobson's relaxation or progressive relaxation technique: is a type of therapy that focuses on tightening and relaxing specific muscle groups, in the case of marathoners consists of three times -three times right arm, left arm, and then three-time right leg and three the left leg in sequence, following by visualization of a relaxing situation. By focussing on specific muscle groups and tensing-relaxing them, athletes can become more aware of their body and physical sensations (Chang et al., 2020).

Coordination skills technique: coordination skills during a race are important behaviors that a runner should train for a marathon race, they included a group of instrumental skills: open a bottle without coughing, keeping pace with the race, drink isotonic gels; and tactical skills: running ahead, running in the middle of the group, slowing, or speeding up a pace (Riera, 2005, 2010; Jaenes and Caracuel, 2016).

Following Jaenes and Caracuel (2016), the intervention focused on the leading Marathon runners psychological training skills. It was carried out over 7 weeks before the marathon, with a weekly session lasting between 60 and $90 \mathrm{~min}$ each. The first two sessions were implemented in groups of seven runners, and the remaining training sessions were performed individually. Table 2, below, shows the schedule of the sessions and their content.

The PST's sessions topics, as well as selected cognitivebehavioral techniques (such as Association-Dissociation Technique and the Pause of Thoughts Technique), were explained during the first meeting. Furthermore, the Jacobson Relaxation Technique, adapted to marathon runners, was requested to be practiced once each day. The participants were advised to practice these training techniques in three different situations: (1) at home three times per day; (2) when negative thoughts arose during training; and (3) after self-provoking the distracting thoughts during the actual training running. 
TABLE 2 | Schedule of the sessions of the psychological intervention program in marathon runners.

\begin{tabular}{|c|c|c|}
\hline Week & Modality & Content \\
\hline 1 & Group & $\begin{array}{l}\text { Presentation and demonstration of the psychological } \\
\text { training and teaching behavioral-cognitive techniques to the } \\
\text { participants as well as base-line evaluation. }\end{array}$ \\
\hline 2 & Group & Teaching cognitive behavioral techniques (cont.). \\
\hline 3 & Individual & Adjustment session (techniques) and individual assessment. \\
\hline 4 & Individual & Adjustment session (techniques) and individual assessment. \\
\hline 5 & Individual & Adjustment session (techniques) and individual assessment. \\
\hline 6 & Individual & Adjustment session (techniques) and individual assessment. \\
\hline 7 & Individual & Race and evaluation of the effectiveness of the intervention. \\
\hline
\end{tabular}

The PST program had the following three sessions: First, Education phase: runners and psychologist make a selfpresentation, psychologist introduced what is PST, and the potential benefits of psychological skills to cope with different situations before and during a marathon, based on their psychological needs refers to the sport psychologist in previous meetings. The program characteristics, components, and information about the cognitive techniques were provided, and the base-line runners' evaluation (pre) was collected with the mental scale. Second, Acquisition phase: A 7 weeks of specific individual training was carried out by the athletes supervised by a sport psychologist. This crash-training is considered enough training to run and compete in a marathon (Péronnet et al., 2001; Jaenes and Caracuel, 2016). During the 7 weeks of practice, see at Table 2, most of the practice was performed while athletes were running, except for the relaxation technique -one time every day at home-. The psychologist made a continuous adjustment of the training to adapt the PST program according to the athlete sensations and performance, but the modifications did not alter the PST program's main structure. Third, Evaluation phase: post evaluation with the mental scale was collected $48 \mathrm{~h}$ before the athletes competed at the marathon.

The PST's schedule and the content of 1 week are summarized in Table 3. In the subsequent sessions, individual adjustments were made to the different strategies and continued until the day of the race. For more information about the intervention, please contact the first author.

\section{Data Analysis}

Non-parametric analyses were performed using the statistical program SPSS V. 25, to compare related samples and thus determine the intervention effectiveness evaluation. Following Morris and DeShon (2002), the Cohen's $d$ effect size were reported for single-group pretest-posttest repeated measure correcting for the correlation; considering large effect sizes those $>0.80$. The internal consistency of the scale was evaluated by the Alpha's Crombach coefficient obtaining a value of $\alpha=0.690$, which is considered acceptable for scales with less than ten items (Loewenthal and Lewis, 2018).

\section{Ethical Approval}

The study was approved by Andalusian Center of Sport Medicine (CAMD). The present study was conducted at the Sport Psychology Unit at CAMD, a public medical center under the direction of Andalusian Council of Education and Sport. Professionals and athletes are regulated under laws of strict confidentiality, and the CAMD's Ethical Committee approved the intervention. CAMD's objective is to care for the athlete's health in a holistic fashion. Ethical principles did not permit us to select a control group between athletes if they had required psychological attention at the Center.

\section{RESULTS}

Participants' age ranged from 21 to 40 (Mean $=30, S D=5.76$ ), they had a minimum of 9 years of running experience and a maximum of 28 years $($ Mean $=16.86, S D=5.11$ ). They had finished between one and eight marathons (Mean $=3.93, S D=$ 1.81). None of the results of the psychological measures used were significantly correlated with athlete's age, years of experience, or number of marathons finished.

Significant decreases in negative thoughts in all conditions (before, during, and after the race), as well as significant reductions in the experience of mental stress and self-doubts were observed after the treatment. Details about the efficacy of the intervention are presented in the figure below (Figure 1).

We tested that the assumption of independence of measurements for the before the race negative thoughts was met $(r=-0.058, p>0.05)$; and we found a $Z$ value equals to $-3.316(p<0.05)$, Cohen's $d=2.385$. These results permit us to affirm that our sample marathoners, after the intervention, presented a significant decrease in negative thoughts prior to the race. The negative thoughts that were present during the race also showed independence between them $(r=0.204, p>0.05)$. Their post-treatment decline was also significant $(Z=-3,305$, $p<0.05$; Cohen's $d=3.051$ ). Finally, statistically significant values were found regarding the perception of reduced mental load, and reduced self-doubts $(Z=-3,307, p<0.05$; Cohen's $d=2.731)$; and the independence between measurements was verified as well $(r=0.197, p>0.05)$. These data show that amateur non-professional marathoners significantly decreased self-doubts, and the perceptions of mental burdens after they were treated with the experimental intervention.

\section{DISCUSSIONS}

The current study supports the hypothesis that psychological skill training (PST), based on cognitive-behavioral techniques and Jacobson Progressive Relaxation technique, significantly decreases the appearance of negative thoughts, mental stress and self-doubt, in participants before, during and after the marathon race. Moreover, the most significant decrease in unwanted thoughts was noticed before and during the race. This result likely positively modified the mental load and reduced selfdoubts, a combination of effects, which can effectively improve performance in such demanding tasks as a marathon. Buman 
TABLE 3 | Example of the weekly psychological training plan.

\begin{tabular}{|c|c|c|}
\hline Day & Training & Psychological Training \\
\hline $\begin{array}{l}\text { Monday, Wednesday, and } \\
\text { Friday }\end{array}$ & 18 kms. Continuous race + stretching & $\begin{array}{l}\text { The athlete must question himself/herself through self-dialog about the negative thoughts } \\
\text { and doubts on the race, and apply the techniques to stop negative thougths in the race. } \\
\text { He trains the coordination ability to be able to drink during the race. }\end{array}$ \\
\hline Tuesday, & $\begin{array}{l}\text { Warm-ups }+(10 \times 1.000,1 ' 15 \text { " recovery }) \\
\text { meters at marathon pace }+3 \mathrm{kms} \text {. of } \\
\text { jogging }\end{array}$ & $\begin{array}{l}\text { Run } 5 \text { series in association, a cognitive attentional strategy (focusing on the sensations } \\
\text { during the race), and } 5 \text { series in dissociation, another cognitive attentional strategy } \\
\text { (ignoring the sensations during the race), and calculate the final time of each series. Write } \\
\text { down about training effectiveness and feelings. }\end{array}$ \\
\hline Thursday & $\begin{array}{l}\text { Warm-ups }+2 \times(10 \times 500 \text { meters, } \\
45 "-60 " \text { recovery }) \text { meters at marathon } \\
\text { pace }+3 \mathrm{kms} . \text { of jogging }\end{array}$ & $\begin{array}{l}\text { Run } 5 \text { series in association, a cognitive attentional strategy (focusing on the sensations } \\
\text { during the race), and } 5 \text { series in dissociation, another cognitive attentional strategy } \\
\text { (ignoring the sensations during the race), and calculate the final time of each series. Write } \\
\text { down about training effectiveness and feelings. }\end{array}$ \\
\hline Saturday & $\begin{array}{l}\text { Warm-ups }+(1 \times 1.000,2 ' 15 " \text { recovery }+ \\
3 \times 3,000,3 \text { ' } 15 \text { " recovery }) \text { marathon pace } \\
+3 \mathrm{kms} \text {. of jogging }\end{array}$ & $\begin{array}{l}\text { Practice the association strategy in the series (focused on the sensations during the race), } \\
\text { calculate the total time of each series through his/her own sensations and without } \\
\text { checking the chronometer }\end{array}$ \\
\hline Sunday & $2 \mathrm{~h}$ of continuous running (group training) & $\begin{array}{l}\text { General practice for group racing tactics: running at the head, at the rear, at the middle, } \\
\text { pulling and slowing down. Drinking and taking gels, running with the competition material to } \\
\text { check the adaptation, provoking negative thoughts and cutting them out with self-dialogue } \\
\text { training: association-dissociation. } \\
\text { Evaluation of the week. }\end{array}$ \\
\hline
\end{tabular}

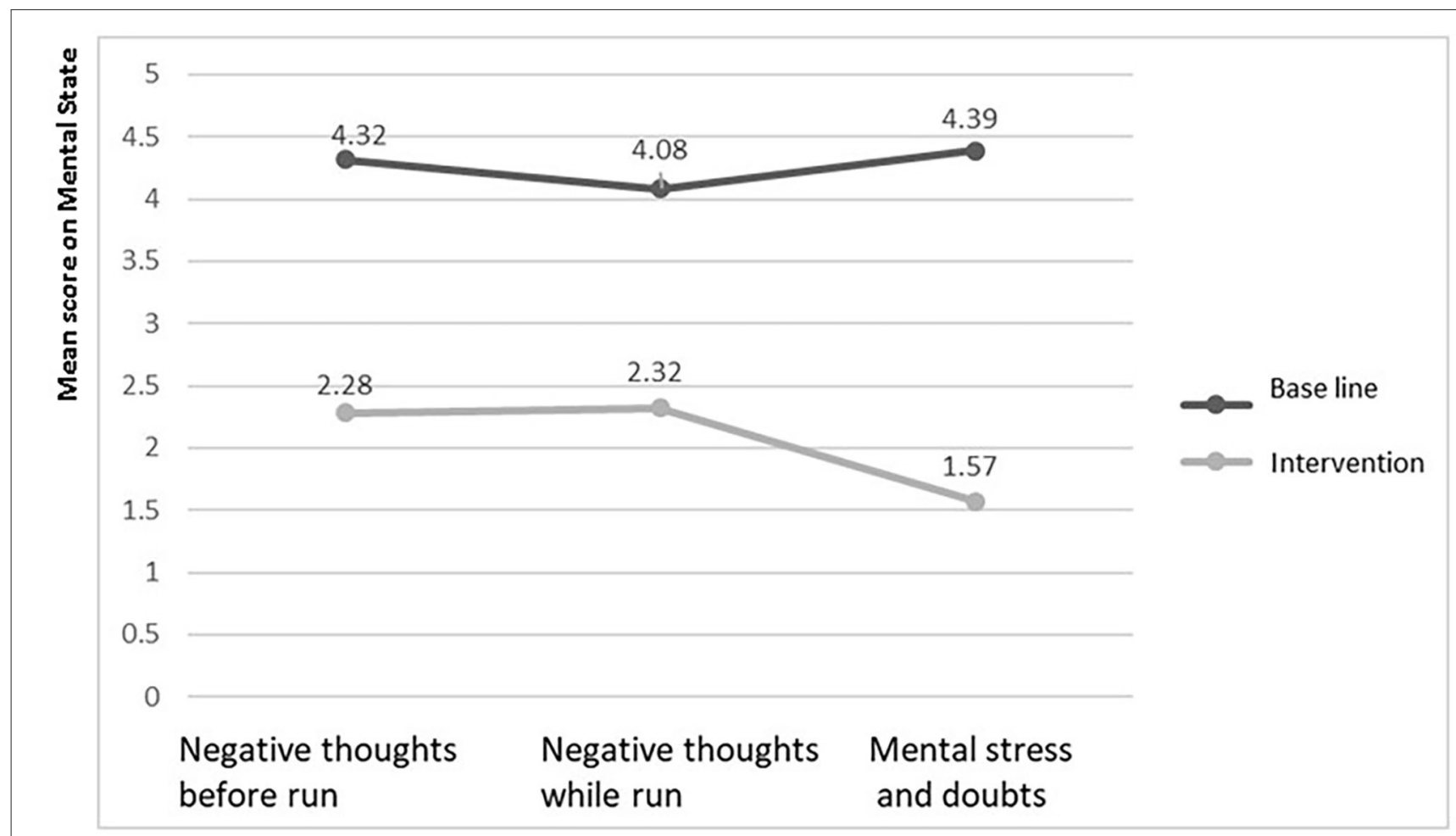

FIGURE 1 | Comparison graph of the means for mental state measures in the basline and after the intervention.

et al. (2008) findings on selected cognitive coping responses to the experience of, speaking colloquially, "hitting the wall" often reported by recreational marathoners, point toward the need to develop efficient interventions to help them overcome such a disturbing experience. There are available a wide range of coping strategies designed to overcome extreme physical challenges.
Among the most efficient mental strategies, which marathoners report using, are physical (such as supplementation/hydration) and behavioral (such as emotion-focused coping, social support, and cognitive strategies such as mental reframing). Moreover, Boyer (2008) underlines that thoughts associated with flexible inward monitoring (bodily sensations), and outward focusing 
(people and landscape) could partially protect runners from the experience of utter exhaustion that they describe as "hitting the wall."

Martín et al. (1995) suggest that the running economy of competitive long-distance runners could be dependent on the implementation of different selected cognitive techniques (positive self-talk and associate techniques) during the race. As some authors underline, "hitting the wall" could also be prevented, or at least decreased, with adequate pacing. Research findings show that runners can be classified as having experienced "hitting the wall" if they ran any $1-\mathrm{km}$ segment $11 \%$ slower than the average for the remaining segments on the race or if they ran any 5 - $\mathrm{km}$ segment $7.3 \%$ slower than the average for the remaining $5-\mathrm{km}$ segments on the race (Doherty et al., 2020). This means that using a rational and optimal pace through the whole marathon, performance with accessible and well-rehearsed strategies to be used at critical moments of mental fatigue, could help runners avoid or overcome the experience of "hitting the wall."

Sport psychology recommends a large number of interventions that can be helpful for endurance athletes, but the effectiveness of these interventions has been questioned, and further effectiveness research has been frequently required (Weinberg and Comar, 1994; Solberg et al., 2000; Devonport, 2006; Ponnusamy and Grove, 2014; Keilani et al., 2016; Brown and Fletcher, 2017). The current study results show that a well-defined intervention based on PST has a significant effect in enhancing marathoners' capacity to cope with stress and with negative demoralizing thoughts about the race. These results support the findings of Meijen et al. (2017), proposing that marathon runners benefit from brief psychological interventions such as mental skill training before, during and after the race. The current study suggests that PST interventions are just as useful in general, and have the added benefit, of helping athletes to deal with the anxiety about the race. Psychological preparation is often ignored, or inadequately employed, in amateur long-distance runners (Solorio and Hickey, 2015). However, it is worth emphasizing that studies of first-time marathon runners highly recommend a multi-modal mental skills training approach as complementary race preparation to the well-established technical and physical training (Carter et al., 2016). Our study supports the idea that amateur runners can achieve robust enhancement of their psychological skills with an intervention such as PST, which is relatively easy to learn and time-efficient.

The current study main limitation is the absence of a control group. It was considered unethical to select a control group between athletes if they had required psychological attention at the Sport Psychology Unit. But a waitinglist control group should be employed in futures studies with similar restrictions. For a waiting-list control group desing, athletes attending to an introductory section should be randomly assigned to the experimental group (athletes who receive the PST program) or a waiting-list group (athletes who received the PST program 8 weeks later). Nevertheless, the procedure of the study is similar to many pedagogical experiments in sport training, the aim of which is expanding selected competencies and abilities of people through the educational process without excluding any participants (Karaulova et al., 2018). This non-excluding intervention is particularly relevant when training high-performance athletes and using innovative forms of intervention (Malikov et al., 2019, 2020; Boichenko, 2020). Many such rigourously designed uncontrolled studies have made important constributions. Thelwell and Greenlees (2003) presented a study that examined the effect of mental skill training (PST) on competitive gymnasium triathlon performance. They evaluated the impact of a training package including goal setting, relaxation, imaginary, and self-talk on the performance of four subjects without a control group; their results pointed out that a PST package was effective in enhancing all participants' performance. The results of our study show the effectiveness of PST in marathon amateur athletes and may serve to expand knowledge about psychological interventions in amateur and professional athletes.

Given the large effect sizes that were found in this study, despite the small sample size and lack of a control group, our results support the effectiveness of PST. We used statistical control of variables such as age, running experience, and number of completed marathons, that highlight the PST intervention as the most likely factor driving the improved performance: the significant decrease in negative thoughts and mental stress. We are planning future replication studies with control groups as well as studies of alternative interventions. For instance, an active control group may be used to compare the efficacy of PST with another type of training intervention. Longitudinal time series designs with baseline observations should be used to control underlying trends and to analyze the short, medium, and long-term effect sizes of the intervention (Eccles et al., 2003; Portela et al., 2015).

The current study provides a PST framework that could help psychologists and trainers to enhance athletes' mental skills, with promising applications for amateur and professional runners. Furthermore, as non-control studies are widely used in meta-analysis of training effectiveness (Weston et al., 2014; Csapo and Alegre, 2015; Taylor et al., 2015; Hammami et al., 2018; Stamatis et al., 2020), our results may be used in future meta-analysis to estimate the effects of PST on athletes.

\section{DATA AVAILABILITY STATEMENT}

The raw data supporting the conclusions of this article will be made available by the authors, without undue reservation.

\section{ETHICS STATEMENT}

The studies involving human participants were reviewed and approved by the study was approved by the Andalusian Center of Sports Medicine. The patients/participants provided their written informed consent to participate in this study. 


\section{AUTHOR CONTRIBUTIONS}

JJ conceived the study, designed the training, collected the data, and wrote the manuscript. DW made relevant contributions to the theoretical framework, interpretation of the results and revision of the final version. DA analyzed the data, wrote the reviewed results and discussion and provided critical revisions on the manuscript. RP analyzed the data and the model and provided critical revisions on the final drafts. AC reviewed the training program, collected the data, and make

\section{REFERENCES}

Birrer, D., and Morgan, G. (2010). Psychological skills training as a way to enhance an athlete's performance in high-intensity sports. Scand. J. Med. Sci. Sports 20(Suppl 2), 78-87. doi: 10.1111/j.1600-0838.2010.01188.x

Boichenko, C. (2020). Assessment of the functional fitness of highly qualified athletes using new methods of express diagnostics. Pedagogy Psychol. Sport 6, 85-92. doi: 10.12775/PPS.2020.06.01.007

Boyer, P. (2008). Cognitive orientation of runners. [In French] L'activite mentale du coureur. Medico-Psychological Annals [in French] Annales Médico-Psychol. 166, 828-832. doi: 10.1016/j.amp.2008.10.022

Brick, N., MacIntyre, T., and Campbell, M. (2014). Attentional focus in endurance activity: new paradigms and future directions. Int. Rev. Sport Exercise Psychol. 7, 106-134. doi: 10.1080/1750984X.2014.885554

Brown, D. J., and Fletcher, D. (2017). Effects of psychological and psychosocial interventions on sport performance: a meta-analysis. Sports Med. 47, 77-99. doi: 10.1007/s40279-016-0552-7

Buman, M. P., Omli, J. W., Giacobbi, P. R. Jr., and Brewer, B. W. (2008). Experiences and coping responses of "hitting the wall" for recreational marathon runners. J. Appl. Sport Psychol. 20, 282-300. doi: 10.1080/10413200802078267

Carmack, M. N., and Martens, R. (1979). Measuring commitment to running: a survey of runner's attitudes and mental states. J. Sport Psychol. 1, 25-42. doi: 10.1123 /jsp.1.1.25

Carter, L., Coumbe-Lilley, J., and Anderson, B. (2016). Strategies for working with first time marathon runners. Sport J. 21, 1-8.

Casado, A., and Ruiz-Pérez, L. M. (2017). Kenyan and Spanish long distance runners and their deliberate practice. [In Spanish] Los corredores kenianos y españoles de larga distancia y su práctica deliberada. Rev. de Psicología del Deporte 26, 55-61.

Casado, A., Ruiz-Pérez, L. M., and Graupera, J. L. (2014). The perception that kenian runners have of their training activities. [In Spanish] La percepción que los corredores kenianos tienen de sus actividades entrenamiento. Cuadernos de Psicología del Deporte 14, 99-110. doi: 10.4321/S1578-84232014000 200011

Chang, M. O., Peralta, A. O., and de Corcho, O. J. P. (2020). Training with cognitive behavioral techniques for the control of precompetitive anxiety. Int. J. Health Med. Sci. 3, 29-34, doi: 10.31295/ijhms.v3n1.121

Csapo, R., and Alegre, L. M. (2015). Effects of Kinesio $囚$ taping on skeletal muscle strength-A meta-analysis of current evidence. J. Sci. Med. Sport 18, 450-456. doi: 10.1016/j.jsams.2014.06.014

Davis, C., and Strachan, S. (2001). Elite female athletes with eating disorders: a study of psychopathological characteristics. J. Sport Exercise Psychol. 23, 245-253. doi: 10.1123/jsep.23.3.245

Devonport, T. J. (2006). Perceptions of the contribution of psychology to success in elite kickboxing. J. Sports Sci. Med. 1, 99-107.

Doherty, C., Keogh, A., Smyth, B., Megyesi, P., and Caulfield, B. (2020). Devising a pace-based definition for 'The Wall': An observational analysis of marathoners' subjective experiences of fatigue. J. Athletic Training 55, 494-500. doi: 10.4085/1062-6050-243-19

Eccles, M., Grimshaw, J., Campbell, M., and Ramsay, C. (2003). Research designs for studies evaluating the effectiveness of change and improvement strategies. BMJ Qual. Safety 12, 47-52. doi: 10.1136/qhc.12.1.47 critical revisions on the manuscript. MT provided a final critical edit, as well the English revision. All authors read and approved the final manuscript.

\section{ACKNOWLEDGMENTS}

This research did not receive any specific grant from funding agencies in the public, commercial, or not-for-profit sectors. Our special thanks goes to Centro Andaluz de Medicina del Deporte (CAMD) for his valuable input on the research.

Fernández Macías, M. A., Godoy-Izquierdo, D., Jaenes, J. C., Bohórquez Gómez Millán, M. R., and Toral, M. V. (2015). Flow and performance in marathon runners. [In Spanish] Flow y rendimiento en corredores de maratón. Rev. de Psicología del Dep. 24, 9-19.

Fernández, E. M. A., Río, G. L., and Fernández, C. A. (2007). Psychometric properties of the Spanish version of the Competitive Anxiety Inventory CSAI-2R. [In Spanihs] Propiedades psicométricas de la versión española del Inventario de Ansiedad Competitiva CSAI-2R en deportistas. Psicothema $19,150-155$.

Fletcher, D., and Hanton, S. H. (2001). The relationship between psychological skills usage and competitive anxiety response. Psychol. Sport Exercise 2,89-101 doi: 10.1016/S1469-0292(00)00014-5

Foster, S., and Walker, B. (2005). "Motivation," in Applying Sport Psychology: Four Perspectives, eds J. Taylor and G. S. Wilson (Champaign, IL: Human Kinetics Publishers), 3-19.

Fournier, J. F., Calmels, C., Durand-Bush, N., and John, H., Salmela, J. H. (2005). Effects of a season-long PST program on gymnastic performance and on psychological skill development. Int. J. Sport Exercise Psychol. 3, 59-78. doi: 10.1080/1612197X.2005.9671758

Freischlag, J. (1981). Selected psycho-social characteristics of marathoners. Int. J. Sport Psychol. 12, 282-288.

Glasser, W. (1985). Positive Addiction, 1 Edn. Harper Perennial.

Gnacinski, S. L., Massey, W. V., Hess, C. W., Nai, M. M., Arvinen-Barrow, M., and Meyer, B. B. (2017). Examining stage of change differences in NCAA studentathletes' readiness for psychological skills training. Sport Psychol. 31, 356-368. doi: 10.1123/tsp.2016-0139

Gontang, A., Clitsome, T., and Kostrubala, T. (1977). A psychological study of 50 sub-3-hour marathoners. Annals N. Y. Acad. Sci. 301, 1022-1028. doi: 10.1111/j.1749-6632.1977.tb38266.x

Hammami, A., Gabbett, T. J., Slimani, M., and Bouhlel, E. (2018). Does smallsided games training improve physical-fitness and specific skills for team sports? A systematic review with meta-analysis. J. Sports Med. Phys. Fitness 58, 1446-1455. doi: 10.23736/S0022-4707.17.07420-5

Hausenblas, H. A., and Carron, A. V. (1999). Eating disorder indices and athletes: an integration. J. Sport Exercise Psychol. 21, 230-258. doi: 10.1123/jsep.21.3.230

Jaenes, J. C. (1994). "Sport psychology and marathon. [In Spanish] Psicología del deporte y maratón," in Marathon: Technical and Scientific Aspects [In spanish] El Maratón. Aspectos Técnicos y Científicos, eds F. Plata, N. Terrados, and P. Vera (Madrid: Alianza Deporte), 277-312.

Jaenes, J. C., and Caracuel, J. C. (2016). Marathon: Psychological Preparation for Training and Competition. [In Spanish] Maratón: Preparación Psicológica Para el Entrenamiento y la Competición. 2nd Edn. Almuzara.

Jaenes, J. C., Godoy-Izquierdo, D., and Román González, F. M. (2009). Hardiness in marathon runners. A study of control, commitment and challenge in female and male marathon runners. Personalidad Resistente en Maratonianos: Un estudio sobre el control, compromiso y desafío de corredoras y corredores de maratón. Rev. de Psicol. del Dep. 18, 217-234. doi: 10.1111/sms.13392

Joseph, P., and Robbins, J. M. (1981). "Worker or runner? The impact of commitment of running and work on self identification," in Psychology of Running, eds M. H. Sacks and M. L. Sachs (Champaign, IL: Human Kinetics), 131-145.

Karaulova, S., Boychenko, K., Malikov, N., Bogdanovskaya, N., Samolenko, T., Apaychev, A., et al. (2018). Innovative technologies based management of the 
training process of female athletes specializing in short distances running. $J$. Phys. Educat. Sport 18:1876. doi: 10.7752/jpes.2018.s4275

Keilani, M., Hasenöhrl, T., Gartner, I., Krall, C., Fürnhammer, J., Cenik, F., et al. (2016). Use of mental techniques for competition and recovery in professional athletes. Wiener Klinische Wochenschrift 128, 315-319. doi: 10.1007/s00508-016-0969-x

Little, J. C. (1976). The athlete's neurosis: a deprivation crisis. Acta Psychiatr. Scand. 45, 187-197. doi: 10.1111/j.1600-0447.1969.tb1 0373.x

Loewenthal, K. M., and Lewis, C. A. (2018). An introduction to Psychological Tests and Scales. London: Psychology Press. doi: 10.4324/9781315782980

Magnusson, J. E., and van Roon, C. A. (2013). Determining the effectiveness of personalized versus prescribed self-talk on athletic performance for elite and novice athletes. Am. J. Appl. Psychol. 1, 1-6. doi: 10.12691/ajap-1-1-1

Malikov, M., Tyshchenko, V., Boichenko, B. N., Savchenko, V., and Moskalenko, N. (2019). Modern and methodic approaches to express-assessment of functional preparation of highly qualified athletes. J. Phys. Educat. Sport 19, 1513-1518. doi: 10.7752/jpes.2019.03219

Malikov, N., Konoh, A., Korobeynikov, G., Korobeynikova, L., Dudnyk, O., and Ivaschenko, E. (2020). Physical condition improvement in elite volleyball players. J. Phys. Educat. Sport 20, 2686-2694. doi: 10.1519/JSC.0b013e31819b78c4

Martín, J. J. F., Craib, M. W., and Mitchell, V. W. (1995). The relationships of anxiety and self-attention to running economy in competitive male distance runners. J. Sports Sci. 13, 371-376. doi: 10.1080/026404195087 32252

Martin, S. B. (2005). High school and college athletes' attitudes toward sport psychology consulting. J. Appl. Sport Psychol. 17, 127-139. doi: $10.1080 / 10413200590932434$

Martin, S. B., Zakrajsek, R., and Wrisberg, C. A. (2012). "Attitudes toward sport psychology and seeking assistance: key factors and a proposed model," in Psychology of Attitudes, eds C. D. Logan and M. I. Hodges (Hauppage, NY: Nova Science Publishers), 1-33.

Master, K. S., and Ogles, B. M. (1998). Associative and dissociative cognitive strategies in exercise and running: 20 years later, what do we know? Sport Psychol. 12, 253-270. doi: 10.1123/tsp.12.3.253

Masters, K. S., and Lambert, M. J. (1989). The relations between cognitive coping strategies, reasons for running, injury, and performance of marathon runners. J. Sport Exercise Psychol. 11, 161-170. doi: 10.1123/jsep.11.2.161

McCormick, A., Meijen, C., and Marcora, S. (2015). Psychological determinants of whole-body endurance performance. Sports Med. 45, 997-1015. doi: 10.1007/s40279-015-0319-6

Meggs, J., and Chen, M. A. (2019). Competitive performance effects of psychological skill training for youth swimmers. Perceptual Motor Skills 126, 886-903. doi: 10.1177/0031512519852533

Meijen, C., Day, C., and Hays, K. F. (2017). Running a psyching team: providing mental support at long-distance running events. J. Sport Psychol. Action 8, 12-22. doi: 10.1080/21520704.2016.1205697

Morgan, W. P., O'Connor, P. J., Sparling, P. B., and Pate, R. R. (1987). Psychological characterization of the elite female distance runner. Int. J. Sports Med. 8, 124-131. doi: 10.1055/s-2008-1025717

Morgan, W. P., and Pollock, M. L. (1977). Psychologic characterization of the elite distance runner. Annals N. Y. Acad. Sci. 301, 382-403. doi: 10.1111/j.1749-6632.1977.tb38215.x

Morris, S. B., and DeShon, R. P. (2002). Combining effect size estimates in metaanalysis with repeated measures and independent-groups designs. Psychol. Methods 7, 105-125. doi: 10.1037/1082-989X.7.1.105

Neil, R., Mellalieu, S. D., and Hanton, S. (2006). Psychological skills usage and the competitive anxiety response as a function of skill level in rugby union. J. Sports Sci. Med. 5, 415-423.

Okwumabua, T. M., Meyers, A. W., Schleser, R., and Cooke, C. J. (1983). Cognitive strategies and running performance: an exploratory study. Cogn. Ther. Res. 7, 363-369. doi: 10.1007/BF01177558

Péronnet, F., Thibault, G., Ledoux, M., and Brisson, G. R. (2001). Marathon. Barcelona: INDE.

Ponnusamy, V., and Grove, J. R. (2014). Sport psychology service provision: preferences for consultant characteristics and mode of delivery among elite Malaysian athletes. J. Sports Sci. Med. 13:638.
Portela, M. C., Pronovost, P. J., Woodcock, T., Carter, P., and Dixon-Woods, M. (2015). How to study improvement interventions: a brief overview of possible study types. BMJ Quality Safety 24, 325-336. doi: 10.1136/bmjqs-2014-003620

Raglin, J. S., and Hanin, Y. L. (2000). "Competitive anxiety," in Emotions in Sport, eds Y. L. Hanin (Champaign, IL: Human Kinetics), 93-111. doi: 10.5040/9781492596233.ch-004

Riera, J. (2005). Sports Skills. [In Spanish] Habilidades en el deporte. Editorial INDE. Available online at: https://www.inde.com/es/productos/detail/pro_id/33

Riera, J. (2010). Fundamentals of Learning Sports Technique and Tactics. [In Spanish] Fundamentos del aprendizaje de la técnica y la táctica deportivas, 5th Edn. Editorial INDE.

Rodríguez, O. R., Ramos Álvarez, J. J., Segovia-Martínez, J. C., López-Silvarrey, F. J., and De la Vega, R. (2017). The effect of cognitive strategies of association and dissociation on central nervous activation: a controlled trial with long distance runners. J. Sports Med. Therapy 2, 95-108. doi: 10.29328/journal.jsmt.1001014

Ruiz-Juan, F., Sancho, A. Z., and Flores-Allende, G. (2016). Precompetitive anxiety in long-distance runners depending on their training variables. [In Spanish] Ansiedad precompetitiva en corredores de fondo en ruta en función de sus variables de entrenamiento. Retos 30, 110-113. doi: 10.47197/retos.v0i30.43674

Ruiz-Juan, F., and Zarauz, A. (2012). Variables that causes negative addiction to run among Spanish marathon runners. [In Spanish] Variables que hacen adicto negativamente a correr al maratoniano español. Retos 21, 38-42.

Ruiz-Juan, F., and Zarauz, A. (2014). Anxiety in marathoners based on sociodemographic variables. [In Spanish]. Ansiedad en maratonianos en función de variables socio-demográficas. Retos 25, 28-31. doi: 10.47197/retos.v0i25.34470

Ruiz-Juan, F., Zarauz, A., Jaenes, J. C., Ibarzábal, F. A., and Flores-Allende, G. (2019). Predictive variables of training dependency in Spanish and Mexican long-distance runners. [In Spanish] Variables predictoras de la dependencia al entrenamiento en corredores de fondo en ruta españoles y mexicanos. Rev. Iberoam. de Psicol. del Ejercicio y el Deporte 14, 18-23.

Sachs, M. L. (1982). "Running addiction," in Psychology of Running, eds M. H. Sacks and M. L. Sachs (Champaign, IL: Human Kinetics Publishers), 116-126.

Sacks, M. H. (1982). "Running addiction: a clinical report," in Psychology of Running, eds M. H. Sacks and M. L. Sachs (Champaign, IL: Human Kinetics Publishers), 127-130.

Schomer, H. (1986). Mental strategies and the perception of effort of marathon runners. Int. J. Sport Psychol. 17, 41-59.

Schomer, H. (1987). Mental strategy training programme for marathon runners Int. J. Sport Psychol. 18, 133-151.

Schuler, J., and Langens, T. A. (2007). Psychological crisis in a marathon and the buffering effects of self-verbalizations. J. Appl. Soc. Psychol. 37, 2319-2344. doi: 10.1111/j.1559-1816.2007.00260.x

Solberg, E. E., Ingjer, F., Holen, A., Sundgot-Borgen, J., Nilsson, S., and Holme, I. (2000). Stress reactivity to and recovery from a standardised exercise bout: a study of 31 runners practising relaxation techniques. Br. J. Sports Med. 34, 268-272. doi: 10.1136/bjsm.34.4.268

Solomon, E. G., and Bumpus, A. K. (1978). The running meditation response: an adjunct to psychotherapy. Am. J. Psychother. 32, 583-592. doi: 10.1176/appi.psychotherapy.1978.32.4.583

Solorio, C., and Hickey, A. (2015). Biomechanical and psychological analysis of high school, intercollegiate, and elite long-distance runners. Phys. Educator 72:4. doi: 10.18666/TPE-2015-V72-I4-5214

Stamatis, A., Grandjean, P., Morgan, G., Padgett, R. N., Cowden, R., and Koutakis, P. (2020). Developing and training mental toughness in sport: a systematic review and meta-analysis of observational studies and pretest and post-test experiments. BMJ Open Sport Exercise Med. 6:e000747. doi: 10.1136/bmjsem-2020-000747

Summers, J. J., Machin, V. J., and Sargent, G. I. (1983). Psychosocial factors related to marathon running. J. Sport Exercise Psychol. 5, 314-331. doi: $10.1123 /$ jsp.5.3.314

Szabo, A., Frenkl, R., and Caputo, A. (1997). Relationship between addition to running, commitment to running, and deprivation from running: a study on the Internet. Eur. Yearbook Sport Psychol. 1, 130-147.

Takai, K. (1996). Cognitive strategies of long-distance runners in pace recall situation. Jpn J. Phys. Educat. Health Sport Sci. 41, 104-114. doi: 10.5432/jjpehss.KJ00003391490

Takai, K. (1998). Cognitive strategies and recall of pace by long-distance runners. Perceptual Motor Skills 86, 763-770. doi: 10.2466/pms.1998.86.3.763 
Taylor, J., Macpherson, T., Spears, I., and Weston, M. (2015). The effects of repeated-sprint training on field-based fitness measures: a metaanalysis of controlled and non-controlled trials. Sports Med. 45, 881-891. doi: 10.1007/s40279-015-0324-9

Thelwell, R. C., and Greenlees, I. A. (2003). Developing competitive endurance performance using mental skills training. Sport Psychol. 17, 318-337. doi: $10.1123 /$ tsp.17.3.318

Vesković, A., Koropanovski, N., Dopsaj, M., and Jovanovi,ć, S. (2019). Effects of a psychological skill training program on anxiety levels in top karate athletes. Rev. Brasileira de Med. Esporte 25, 418-422. doi: 10.1590/1517-869220192505173969

Wadey, R., and Hanton, S. (2008). Basic psychological skills usage and competitive anxiety responses. Res. Q. Exercise Sport 79, 363-373. doi: 10.1080/02701367.2008.10599500

Weinberg, R., and Gould, D. (2014). Foundations of Sport and Exercise Psychology, 6 Edn. Champaign, IL: Human Kinetics.

Weinberg, R. S., and Comar, W. (1994). The effectiveness of psychological interventions in competitive sport. Sports Med. 18, 406-418. doi: 10.2165/00007256-199418060-00005

Weston, M., Taylor, K. L., Batterham, A. M., and Hopkins, W. G. (2014). Effects of low-volume high-intensity interval training (HIT) on fitness in adults: a metaanalysis of controlled and non-controlled trials. Sports Med. 44, 1005-1017. doi: 10.1007/s40279-014-0180-Z

Wrisberg, C. A., Simpson, D., Loberg, L. A., Withycombe, J. L., and Reed, A. (2009). NCAA division-I student-athletes' receptivity to mental skills training by sport psychology consultants. Sport Psychol. 23, 470-486. doi: 10.1123/tsp.23.4.470
Wulf, G. (2013). Attentional focus and motor learning: A review of 15 years. Int. Rev. Sport Exercise Psychol. 6, 77-104. doi: 10.1080/1750984X.2012.7 23728

Yates, A. (1987). Eating disorders and long-distance running: the ascetic condition. Integrat. Psychiatr. 5, 201-204.

Yates, A. (1991). Compulsive Exercise and the Eating Disorders: Toward an Integrated Theory of Activity. New York, NY: Brunner/Mazel.

Yates, A., Leehey, K., and Shisslak, C. M. (2010). Running-An Analogue of Anorexia? N. Engl. J. Med. 308, 251-257. doi: 10.1056/NEJM1983020330 80504

Zinsser, N., Bunker, L. K., and Williams, J. M. (2006). “Cognitive techniques for improving performance and building confidence," in Applied Sport Psychology: Personal Growth to Peak Performance, 5th Edn, ed J. M. Williams (McGraw-Hill College, CA: Mayfield), 284-311.

Conflict of Interest: The authors declare that the research was conducted in the absence of any commercial or financial relationships that could be construed as a potential conflict of interest.

Copyright (c) 2021 Jaenes, Wilczyńska, Alarcón, Peñaloza, Casado and Trujillo. This is an open-access article distributed under the terms of the Creative Commons Attribution License (CC BY). The use, distribution or reproduction in other forums is permitted, provided the original author(s) and the copyright owner(s) are credited and that the original publication in this journal is cited, in accordance with accepted academic practice. No use, distribution or reproduction is permitted which does not comply with these terms. 